\title{
Suspended sediment flux at the Rhone River mouth (France) based on ADCP measurements during flood events
}

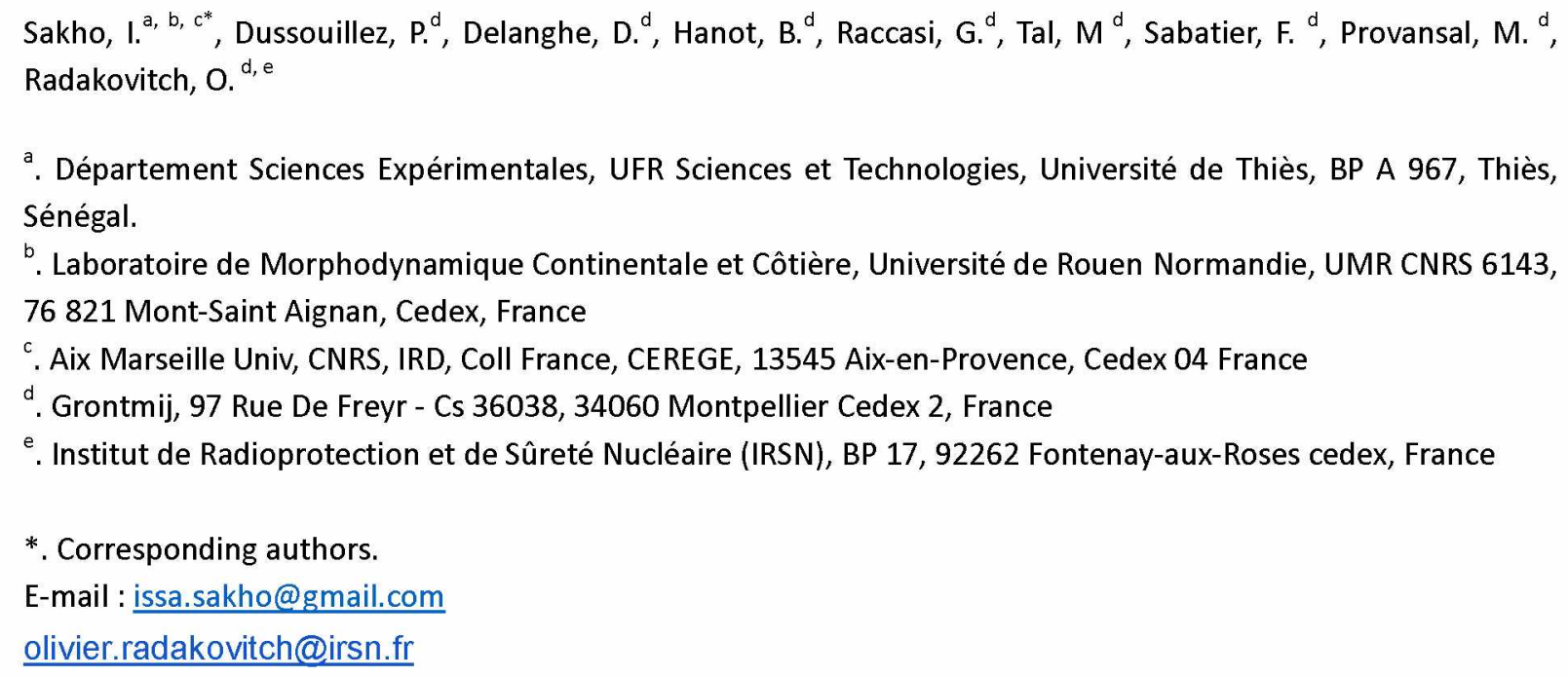

19 Abstract

Suspended sediment distribution and fluxes were estimated within the dominant channel 21 at the mouth of the Rhone River for two annual flood events. The estimates were based on ADCP acoustic backscatter intensity and using calibration and post-processing methods to account for the grain-size distribution (GSDs). The fluxes were very similar to those obtained

24 from suspended sediment measurements based on surface sampling at an automated station 25 located $35 \mathrm{~km}$ upstream. Suspended Sediment Concentrations (SSC) and GSDs showed little 26 variation along the channel cross section, except for a graduate suspension that appeared at 27 the maximum of discharge, corresponding to velocities lower than $1 \mathrm{~m} \cdot \mathrm{s}^{-1}$ near the bottom. 28 However, without post processing to account for the GSD, an under-estimation of $10 \%$ was 29 observed during the two floods periods. The two flood events, separated by only two weeks, 30 had clear differences in suspended fluxes and SSC, with twice more flux during the first 31 event.

32 Keywords: Suspended sediment flux, ADCP measurements, Backscatter calibration, Grain- 
size distribution, flood events, Rhone River, France

\section{Introduction}

Determination of the quantity and quality (e.g., grain size, pollutants) of sediment delivered by rivers to the ocean is critical for managing and preserving deltas, shorelines, and marine ecosystems (Vörösmarty et al., 2003; Limber et al., 2008). Both the morphology of these systems and the habitat they support depend directly on the sediment flux delivered by the river, which itself depends on sediment production in the catchment (e.g. geology, precipitation, land use) and on the continuity of its transfer to the coast (e.g. retention dams, dredging; Blum and Tornqvist, 2000; Syvitski \& Saito, 2003; Antonelli et al., 2004; Provansal et al, 2014)

Suspended sediment fluxes (SSF) have been measured worldwide for a wide range of rivers (e.g. Walling et al., 1992; Inman and Jenkins, 1999; Picouet et al., 2001; Meybeck et al., 2003; Rovira et al., 2005 ; Hu et al., 2011 ; Boateng et al., 2012 ; Unverricht et al., 2014), and best practices for estimating these fluxes have been discussed by Moatar et al. (2006), Horowitz (2008) and Horowitz et al. (2015). The vast majority of these sediment flux estimates are based on suspended sediment concentrations (SSC) measured from a surface sample of the flow, and do not take into account variations in grain-size distributions and/or suspended sediment concentrations within the water column and the channel section.

Meybeck et al (2003) compiled a database of SSC and SSF measured in rivers worldwide and covering a range of flow regimes. According to their study, the difference in flux estimates from surface versus depth-integrated samples can induce one hundred percent variations in $\mathrm{SSC}$, but they note that this range is negligible compared to the variation of up to six orders of magnitude due to temporal variation (e.g. discharge fluctuation). However, Horowitz (2008) demonstrated the marked spatial (vertical and lateral) and temporal variability in SSC in rivers for both constant and varying discharge and recommended that both depth and width- 
59 integrated samples are needed to generate representative samples. Alternative methods that

60 have been proposed and explored in order to measure SSC within the water column include

61 measurements using an Optical Backscatter Sensor (Schoellhamer and Wright, 2013) and/or

62 an Acoustic Doppler Current Profiler (ADCP, e.g. Tessier et al., 2008; Defendi et al., 2010 ;

63 Duclos et al., 2013) - which was the focus of this study. However, as we will discuss in detail

64 later, accurate estimates based on these techniques require analysis of water samples collected

65 in real time in order to determine the grain size distribution (GSD) and calibrate its

66 relationship with SSC.

67 The Rhone River, in the south of France, is the main source of freshwater and continentally

68 derived sediments to the Mediterranean Sea. The downstream-most SSF has been monitored

69 continuously since 2005 at the SORA monitoring station located in Arles (Figure 1a). These

70 flux estimates are based on SSC measured from an automated surface flow sample collected

71 once a day. While, this system provides an efficient and reliable method for obtaining a long

72 and continuous record (Eyrolle et al 2012), it is not well suited for accurately estimating

73 fluxes during floods, which can typically have strong vertical gradients in GSD and rapid

74 changes in SSC. Furthermore, the system is susceptible to technical malfunctions when SSC

75 is high, resulting in unreliable data. Annual SSF measured at Arles ranges between 1 and 11

$76 \mathrm{Mt} . y r^{-1}$ (Pont et al., 2002; Antonelli et al., 2008; Ollivier et al 2011; Eyrolle et al., 2012). The

77 representativity of these SSC has been tested for discharges up to $3000 \mathrm{~m}^{3} \cdot \mathrm{s}^{-1}$, but higher

78 discharges could well induce more pronounced vertical stratification in SSCs and therefore

79 larger errors in the estimation of SSF. Studies by Pont et al. (2002), Antonelli et al. (2008),

80 Ollivier et al (2011), and Eyrolle et al., (2012) estimate that between $80-90 \%$ of the Rhone

81 annual suspended sediment flux is associated with floods. As such, there is a clear need for a

82 more robust method to quantify SSF associated with these events. This study is part of an

83 ongoing effort to develop a continuous monitoring system using an ADCP to estimate SSFs 
84 during floods at the mouth of the Rhone delta. The study, spanning two flood events,

85 highlights the potential of this technique for characterizing spatial and temporal variability in

86 SSF and its relationship to flow hydrodynamics. The insights from this study provide an

87 important first step towards putting in place a fully autonomous system for continuous

88 monitoring of SSF on a large river. Our objective is to get a more precise estimate of sediment

89 delivery to the Rhone delta in order to better inform coastal management strategies. On the

90 long-term, we seek to relate SSF to discharge patterns and meteorological conditions in order

91 to identify the main sources of variability in flux delivered to the delta.

In this paper we present an analysis of ADCP measurements conducted during two annual floods in 2012. XXXXX During both floods, we collected suspended sediment samples at different locations and depths that provided precise information about SSC and GSD. We used this data to calibrate the ADCP backscatter signal and compare flux estimates with and without taking into account GSD. In addition, the samples provide a first glimpse at how GSD distribution varies with depth over the course of annual floods on the Rhone River.

\section{Suspended Sediment Flux (SSF) estimates based on acoustic monitoring}

Efforts to quantify SSF from the SSC distributions measured over the entire vertical flow column and across an entire cross-section of channel have focused on the use of acoustic Doppler Current Profilers (ADCPs; Alvarez and Jones, 2002; Gartner, 2004 ; Kostaschuk et al., 2005; Tessier et al., 2008; Ghaffari et al., 2011; Duclos et al., 2013). ADCPs use the Doppler effect of sound scattered back from particles transported in suspension to measure flow velocity. Holdaway et al. (1999) were amongst the first to demonstrate that this backscatter signal could be also analyzed to extract information on SSC. Such acoustic measurements have been used for example to study sedimentary processes in sandy systems over short spatial and temporal scales such as tidal periods (Tessier et al., 2008). Acoustic Suspended Sediment Monitor is another system adapted for fine-grained cohesive sediment 
and concentration ranging between 0.5 and $8 \mathrm{~g} .1^{-1}$ (Shi, 2010).

Estimating solid flux from acoustic measurements requires calibrating the sound intensity scattered by particles in the flow with SSC. This is typically done by comparing the backscatter signal to measured SSC from samples collected at various depths in the water column and along a cross-section. Software for using this data to performing the calibration (e.g., Sediview, Plum Detection Toolbox) provide good results as long as data from direct measurements are available (Defendi et al., 2010). However, a limitation of this technique is that the acoustic signal is grain-size dependent. In other words, for a given sediment concentration, the relative backscatter sensitivity can be different whether the GSD is coarser or finer, expressed in terms of relative percentages of clay, silt and sand (Guerrero et al., 2011). The implication of this, is that flux estimates based on these calibrations are only accurate if the GSD remains constant over the range of flows that are monitored acoustically.

\section{Description of the study site and ADCP monitoring}

The Rhone River basin has an area of approximately $97,800 \mathrm{~km}^{2}$ and drains several different mountain ranges including the Alps, the Jura, and the Cevennes. The mean annual flow discharge at the downstream is approximately $1700 \mathrm{~m}^{3} \cdot \mathrm{s}^{-1}$, based on daily discharge records for the period 1920 - 2013 from the Beaucaire gauging station located $60 \mathrm{~km}$ upstream of the mouth (data available at http://hydro.eaufrance.fr). The Rhone is characterized by large inter-annual flow and sediment flux variability due to highly variable rainfall patterns and lithology within the catchment (Eyrolle-Boyer et al., 2012). This natural variability is enhanced by a series of hydroelectric dams (Provansal et al, 2014).

Approximately $50 \mathrm{~km}$ upstream of its mouth, the Rhone River separates into two branches - the Petit Rhone and the Grand Rhone (Figure 1a). The dominant branch (Grand Rhone) traverses the city of Arles and transports on average $90 \%$ of the flow (Boudet et al, 
submitted). Annual floods in Arles have a discharge of approximately $3900 \mathrm{~m}^{3} \cdot \mathrm{s}^{-1}$, and 2-yr and 10-yr return period floods have discharges of 4800 and $7800 \mathrm{~m}^{3} \cdot \mathrm{s}^{-1}$ respectively (Boudet et al., submitted). Whatever is the peak discharge, flood durations range from 1 to 34 days with a mean of 5 days (Eyrolle et al., 2012; Boudet el al, submitted). About $90 \%$ percent of the alluvial floor in our study area (see below) is covered by sand with a median grain size of 0.55-0.50 mm (Arnaud-Fassetta et al., 2003). This sand can be transported by suspension at bankfull discharge $\left(5400 \mathrm{~m}^{3} \cdot \mathrm{s}^{-1}\right)$ according to the Shields diagram (Arnaud-Fassetta et al., 2003).

In order to improve estimates of total SSF delivered by the Rhone River to the Mediterranean Sea, particularly by large and rapid floods, we equipped a passenger ferry, known as Barcarin, which traverses the Grand Rhone $13 \mathrm{~km}$ upstream from the mouth (Fig 1) with an $\mathrm{ADCP}$ in order to conduct continuous in-situ measurements.

The Barcarin ferry was equipped with an ADCP - RDI 600 kHz Workhorse Rio Grande (Teledyne RD Instruments, 2007) set to operate with a $0.5 \mathrm{~m}$ vertical cell size. The ADCP was mounted on the upstream side of the ferry and conducts measurements each time the ferry crosses the river (Fig. 1b). The distance of the channel at this location is $350 \mathrm{~m}$ and it takes the ferry approximately 3 minutes to traverse the full width (Fig. 1b). Approximately two hundred crossings are made per day, resulting in an equivalent number of profiles acquired. The ferry does not run between $2 \mathrm{AM}$ and $4 \mathrm{AM}$ and for discharges higher than $6000 \mathrm{~m}^{3} \cdot \mathrm{s}^{-1}$. The start and end of each profile are automatically determined from GPS positions of the boat, with an error estimated at $\pm 5 \mathrm{~m}$ due to the width of the docks (Fig. 1b). This error is quite large, sometimes leading successive crossings to be recorded as a single profile; these can be manually separated later on. ADCP data are automatically transferred via Wifi to a computer located in a building near the dock and from there to the CEREGE laboratory. The ADCP is cleaned every few months of biofilm accumulations. 
Other than short interruptions for technical maintenance and/or improvements, the

159 ADCP has been operating continuously since March 2012. A main advantage of this setup is

160 that the equipment is in place and fully operational when a flood arrives. This eliminates the need of hastily organizing a monitoring trip (equipment and personnel) when flow levels start to rise and ensures that sediment flux is monitored over the full duration of the flood. In addition, the ferry's location, $32 \mathrm{~km}$ downstream of the SORA station (Fig. 1), permits comparison between SSF estimates based on the ADCP and those estimated from surface measurements at the station. Finally, as opposed to measurements collected at a single fixed location, the ferry-mounted ADCP collects backscatter data along the full cross-section, making it possible to study how suspended sediment is distributed both vertically and horizontally.

\subsection{Measurements of in-situ suspended sediment concentrations and grain size}

\section{distributions}

The two annual events that we focus on in this paper occurred in 2012 on November 12th (hereafter referred to as the N-12 event) and on November 29th (N-29 event). These events had a peak discharge of $4000 \mathrm{~m}^{3} \cdot \mathrm{s}^{-1}$ and $4200 \mathrm{~m}^{3} \cdot \mathrm{s}^{-1}$ respectively (Fig 2a). As was previously mentioned, accurate estimation of SSCs from ADCP backscatter data requires a GSD-based correction of the backscatter intensity with SSC calibration. In order to perform this correction, we collected suspended sediment samples during the course of the two floods. Figure $2 \mathrm{a}$ shows the hydrograph of these floods with black squares corresponding to the days when in-situ samples were collected. The samples were collected from the ferry itself with a 5L horizontal (Niskin) sampling bottle. A multi-parameter probe (Diver CTD) was fixed to the Niskin bottle in order to measure salinity, water temperature, and water depth for each sample. Vertical samples were collected at three lateral locations: left and right banks and channel center (Figure $2 \mathrm{~b}$ ) in order to characterize variations in sediment concentration. On each 
location, six samples were collected between the surface of the flow and the channel bottom (flow depths ranged from 7 to $10 \mathrm{~m}$ ) with the exact depth of each sample recorded with the probe

Suspended sediment concentrations (SSC in $\mathrm{mg}^{-1}{ }^{-1}$ ) were determined using a standard filtration method (ISSeP, 2014): $500 \mathrm{ml}$ filtered through $0.45 \mu \mathrm{m}$ filters and dried at $40{ }^{\circ} \mathrm{C}$ for $48 \mathrm{~h}$. One liter of sampled water was set aside for measuring GSD and stored at $4^{\circ} \mathrm{C}$ until it could be analyzed (typically within a few days). The GSD were measured with a Beckman Coulter LS 13320 laser granulometer, with a range of 0.04-2000 microns in 117 fractions collected on 132 detectors. The calculation model uses Fraunhöfer and Mie theory, water as the medium $\left(\mathrm{RI}=1.33\right.$ at $\left.20^{\circ} \mathrm{C}\right)$, a refractive index in the range of that of kaolinite for the solid phase $(\mathrm{RI}=1.56)$, and absorption coefficients of 0.15 for the $780-\mathrm{nm}$ laser wave length and 0.2 for the polarized wavelengths. Ideally, a flow sample is poured all at once into the $1 \mathrm{~L}$ granulometer cup without the need for pre-treatment or sub-sampling. However, particle concentrations during the floods were too high and exceeded the optimal obscuration windows between 8 and 16\% for diffraction and 50\% and 70\% for diffusion using the PIDS technology (Polarization Intensity Differential Scattering). They were thus subsampled through magnetic stirrer agitation before being injected into the granulometer. Six subsamples from a single bottle were measured to define the repeatability of the sub-sampling. The two-sigma errors on the reproducibility were $1.5 \%$ on the mean and $0.2 \%$ on the $\mathrm{D}_{50}$ value. The validity of the analyses was also checked routinely using standard including G15 $\left(\mathrm{D}_{50}=15 \mu \mathrm{m}\right), \operatorname{SRM} 1003 \mathrm{C}\left(\mathrm{D}_{50}=32 \mu \mathrm{m}\right)$ and SRM1004b $\left(\mathrm{D}_{50}=78.4 \mu \mathrm{m}\right)$. The ratio between measured and certified values was respectively $-2,+2$ and $-8 \%$ for these standards.

\subsection{Backscatter calibration}

Several methods have been proposed to calibrate the backscatter signal of an ADCP in order to assess sediment flux in fluvial and estuarine environments. While we mention them 
208 here, a detailed explanation of these methods is beyond the scope of this paper. Tessier et al. 209 (2008) proposed a laboratory experiment calibration using optical backscatter sensor (OBS) 210 turbidity measurement. Other researchers have used a post-processing method developed in 211 Sediview (Land and Bray, 2000; Dredging Research Ltd., 2003; Cutroneo et al., 2012), which 212 is based on a simplified version of acoustic theory in order to correct dispersion and 213 attenuation of the acoustic backscatter signal (Defendi et al., 2010). In this study we used the 214 ViSea Plume Detection Toolbox (PDT) developed by Aqua Vision®. Like Sediview, this 215 software uses acoustic theories to correct for signal losses associated with acoustic spreading, 216 water absorption and particle attenuation (Francois \& Garisson, 1982; Urick, 1983; Rijn, 217 1993). In the first phase of calibration, the default absorption coefficient of $0.181 \mathrm{~dB} \cdot \mathrm{m}^{-1}$ for a $218600 \mathrm{kHz}$ ADCP frequency, which is estimated for a water temperature of $4^{\circ} \mathrm{C}$ and a salinity of $21935 \mathrm{ppt}$, is corrected using field temperature and salinity measurements. Next, the absolute 220 backscatter signal is converted to SSC based on direct measurements of SSC in mg. $1^{-1}$. The 221 relationship between Absolute Backscatter (I) and SSC is defined by (Visea PDT Manual):

$$
10 * \log (\mathrm{SSC})=4.6+0.054 * \mathrm{I}
$$

223 Where SSC represent the Suspended Sediment Concentration $(\mathrm{mg} / \mathrm{l})$ and I the Absolute 224 Backscatter Intensity.

225 Since absolute backscatter and therefore SSC depend on the degree of particle attenuation, the 226 second step corrects for this by integrating the grain-size distribution. The ViSea PDT is not 227 limited to only a single $\mathrm{D}_{50}$ value, offering the possibility of taking into account all size 228 fractions ranging from sand $(2000 \mu \mathrm{m})$ down to clay $(0.24 \mu \mathrm{m})$. Finally, the software 229 calculates a Total Suspended Sediment Flux $\left(\mathrm{kg} \cdot \mathrm{s}^{-1}\right)$ based on the backscatter signal 230 calibration. 


\subsection{Flow velocity and discharge}

234 The structure and evolution of flow velocities across the transect during the N-12 event are 235 shown in figure $3 \mathrm{a}$ (mean velocities are indicated in each plot). Figure $3 \mathrm{~b}$ shows that mean 236 flow velocities (calculated for ADCP profile per day) measured at Barcarin are well correlated $237\left(\mathrm{R}^{2}=0.97\right)$ with daily discharges measured upstream at the SORA station. The dataset spans a 238 large range of discharges during various days in 2012, for which the estimated mean 239 velocities varied between 0.18 and $1.4 \mathrm{~m} \cdot \mathrm{s}^{-1}$. Maximum mean flow velocity $\left(1.4 \mathrm{~m} \cdot \mathrm{s}^{-1}\right)$ 240 corresponded to the flood peaks of both the N-12 and N-29 events. During the flood peaks,

241 velocities were highest within the top 5 meters of the water column and decreased toward the 242 channel bottom and banks (Fig. 3a)

\subsection{Suspended sediment concentrations and grain-size distributions from direct} sampling

Figure 4 shows the SSC measurements for the samples collected at different depths and lateral positions within the channel. The different dates correspond to the black squares shown in figure 2: 7 days and 6 days for the N-12 and N-29 events respectively. There was no statistically significant difference in SSC with lateral position. The SSC was also uniform with depth during low discharges and showed a slight increase with depth during the flood

251 peaks (right bank for the N-12 peak for example). The daily mean SSC (mean of all depths 252 and locations) ranged from a minimum of $40 \pm 4 \mathrm{mg} \cdot \mathrm{l}^{-1}$ on the $27^{\text {th }}$ Nov to a maximum of $2532853 \pm 140 \mathrm{mg} \cdot \mathrm{l}^{-1}$ on the 12 th Nov, corresponding to the peak of the first flood. The mean SSC 254 was clearly lower for the second peak flood on the 29 th Nov : $1100 \pm 180 \mathrm{mg} . \mathrm{l}^{-1}$. To compare, 255 SSC values in the Grand Rhone typically ranged from 8 to $20 \mathrm{mg} \cdot \mathrm{l}^{-1}$ during usual flow 256 conditions. 
Figure 5 shows the distribution of clay, silt, and sand as $\%$ of total sample volume for

samples collected at $0.5 \mathrm{~m}$ from the surface in the center of the channel. The GSD during the N-12 and N-29 floods were very similar and consisted of the following clay-silt-sand percentages respectively based on an average of all samples: 15-81-4 and 15-83-2 (Fig. 5). For both floods, the range of percentage of clay-sized particles was between $11-22 \%$ and increased with increasing flow discharge, reaching a maximum value of $22 \%$ at the peak of each flood (Fig. 5). Silt-sized particles represented the majority of the suspended sediment load (around $80 \%$ ) and the sand fraction never exceeded $10 \%$ (Fig. 5). This last fraction increased during the two days following the $\mathrm{N}-12$ peak.

\subsection{Backscatter signal calibration and GSD-based correction}

Calibration of the backscatter signal using the ViSea PDT® with SSC and GSD resulted in linear regressions with $\mathrm{R}$ coefficients equal to 0.90 and 0.88 for the $\mathrm{N}-12$ and $\mathrm{N}-29$ floods respectively. We used these calibrations to estimate SSC from ADCP backscatter (using the Plum Detection Toolbox) and then used these values to calculate a total SSF in $t . d^{-1}$ for each sampling day.

Figure 6 illustrates the difference in SSC distributions estimated across the channel without (Fig. 6a) and with (Fig. 6b) the correction for the GSD. This example corresponds to the N-12 event. When only measured SSC were considered in the calibration, the resulting estimate of total SSF was 825000 t.d $\mathrm{d}^{-1}$. When the calibration was based on both SSC and GSD, this total SSF increased to $925000 \mathrm{t.d}^{-1}$ (Fig. 7). For the N-29 event, the total SSF increased from 390200 to $431000 \mathrm{t}^{-1}$ with the correction. This discrepancy in the estimates of SSF highlights the role that fine particles play in attenuating the acoustic signal, inducing here a mean underestimation of about $10 \%$. During normal discharges, the homogeneity of GSD does not influence so much the estimation of the total SSF. 

$294 \pm 10-15 \%$.

\subsection{Estimated total suspended sediment flux}

Once we had estimated SSC from the calibrated ADCP signal (using both measured SSC and GSD) corresponding to each of the samples that were collected, we proceeded to estimate a daily SSF $\left(\mathrm{t}^{-1}{ }^{-1}\right)$ over the course of each flood event (Figures 7 and 8 ). For that, we assumed that the concentrations estimated from the calibrated signals for one ADCP profile were representative of the daily flux, and thus considered them to be uniform over a 24-h period. We consider this a reasonable assumption since the variability of discharge within a single day was low: the coefficient of variation for hourly discharge measured at SORA over the span of a single day was between 1 and $9 \%$. The only exception was Nov. 27 when the coefficient reached $22 \%$. Furthermore, when we checked the backscatter profiles measured one hour before and after the sampling, they were very similar to the profiles that were calibrated. We thus assume that the maximum error associated with our daily SSF estimates is

Our estimates show that over the course of the N-12 flood, SSF increased from 69000 t.d $\mathrm{d}^{-1}$ during the two days prior to peak discharge to $925000 \mathrm{t} \cdot \mathrm{d}^{-1}$ at the flood peak (Fig. 7A-C) then rapidly decreased to $123000 \mathrm{t} \cdot \mathrm{d}^{-1}$ and $6700 \mathrm{t} \cdot \mathrm{d}^{-1}$ for 2 and 7 days post-peak respectively (fig 7 E-G). Maximum daily SSF corresponded to maximum discharge (Fig. $7 \mathrm{H}$ ). A strong vertical gradient in SSC can be seen on the $11^{\text {th }}$ and $12^{\text {th }}$ of November - immediately ahead of and during the maximum discharge (Fig. 7 B-C). This maximum vertical gradient did not coincide with the increase in the sand fraction shown in figure 4. SSC was approximately $3000 \mathrm{mg} \cdot \mathrm{l}^{-1}$ near the channel bottom and decreased to $2500 \mathrm{mg} \cdot \mathrm{l}^{-1}$ at $4 \mathrm{~m}$ below the surface. SSC once again became uniform when discharge decreased, stabilizing at a value of approximately $700 \mathrm{mg} . \mathrm{l}^{-1}$ (Fig. 7E). As discharge decreased during the falling limb of the hydrograph, SSC were high compared to similar discharges during the rising limb. This trend is typical of leading hysteresis in sediment transport during floods and is generally associated 
with resuspension of sediments from the bed (Horowitz 2008). Similar trends are observed for the N-29 flood, although vertical gradients in SSC were limited to one day (Fig. 8C\&F). As mentioned earlier, total SSF was twice as high during the N-12 event as in the N-29 event despite similar daily peak discharges (Fig. 2a).

\section{Discussion}

Estimates of SSC and SSF from ADCP measurements conducted over the course of two flood events from the Barcarin ferry near the mouth of the Rhone River showed good correlation with their respective flood hydrographs (Fig. 7H \& Fig. 8F). Furthermore, the SSF estimates are very similar to those obtained from the automated sampling station SORA located $32 \mathrm{~km}$ upstream (Fig. 9). This comparison shows a strong linear relationship (y= $0.6803 x+67067 ; R^{2}=0.6, n=12 ; p>0,05$, not shown), a relation further improved $(y=$ $\left.0.8719 \mathrm{x}+26252 ; \mathrm{R}^{2}=0.9 ; \mathrm{p}>0,001\right)$ when we correct for the time-lag between the two locations (approximately $10 \mathrm{~h}$ for a mean flow velocity $=1 \mathrm{~m} \cdot \mathrm{s}^{-1}$ ). This strong relationship is likely due to the fact that the vertical gradient in SSC was weak for the two monitored floods (fig 3), and confirms that surface samples at SORA are representative of SSC over the entire vertical flow column for annual return floods, such as the two events monitored here. It remains unknown how SSC is distributed vertically for larger floods, but our data indicate that a suspended gradient may develop at higher discharges. This in agreement with ArnaudFassetta et al (2003) who shown that Shields diagram indicates that transport of sand can be common (and in suspension) at bankfull discharge $\left(5400 \mathrm{~m}^{3} \cdot \mathrm{s}^{-1}\right.$, higher than our peak discharges).

The two consecutive floods had very similar peak discharges and hydrograph shapes, but estimates of daily SSF were twice as high in the first event. This difference does not appear to be related to the relative contributions of different tributaries during each event. 
Indeed, the major tributaries of the Rhone contributed in a similar manner to the total

333 discharge during both events as follows: $10-15 \%$ from the Durance, $15-20 \%$ from the Isere,

334 $25-30 \%$ from the Saone and $40 \%$ from the Rhone upstream of Lyon (estimates are based on daily discharges reported at http://hydro.eaufrance.fr). Therefore, the difference in SSC is likely explained by a difference in the amount of material eroded in the tributary basins and the channel banks, and/or a decrease of sediment available for resuspension from the riverbed between the first and second flood. Zebracki et al (2015) have demonstrated the role of remobilized sediment as a significant secondary source, based on a fingerprinting approach using plutonium activity ratios associated with particles.

The estimated total solid flux transported during these two events ( 8 days in total) was $2.710^{6}$ tons. This value represents $50 \%$ of the annual SSF in $2012\left(5.610^{6}\right.$ tons) estimated from measurements at the SORA station (unpublished data, SORA station database). In addition to the November floods, high discharges occurred in January and December 2012 (average daily discharges were between 2900 to $3800 \mathrm{~m}^{3} \cdot \mathrm{s}^{-1}$ from January $2-10$, and 3100 to $3600 \mathrm{~m}^{3} \cdot \mathrm{s}^{-1}$ from December $16-30$.). The cumulative total SSF transported by these four events represents $82 \%$ of the annual suspended sediment flux, a typical value for the flux transported by annual floods in the Rhone (Eyrolle et al, 2012).

A synthesis of SSF transported by the floods since 2005 based on data from SORA station showed that fluxes are influenced by factors other than maximum discharge such as location of precipitation in the catchment area and sometimes dam management (Eyrolle et al, 2012). The results of this study support these observations and highlight the role of sediment available for resuspension in the riverbed, as well as the role of antecedent conditions (i.e. flood succession). Continuous monitoring is therefore necessary to accurately quantify longterm trends and to estimate SSF contributions from individual events. In addition to informing coastal management, this type of data is important to constrain the flux of various 
357 hydrophobic pollutants including metals, PCBs and other organic contaminants (Ollivier et 358 al., 2011).

\section{Conclusion}

361 a. In this study we used the Plum Detection Toolbox to calibrate suspended sediment 362 concentrations (SSC) from ADCP acoustic backscatter and used this to estimate suspended 363 sediment flux for two annual floods on the lower Rhone River.

b. The ADCP in this study was mounted on a ferryboat that traverses the dominant branch of lower Rhone River (Grand Rhone) multiple times a day. This setup has enabled continuous acquisition for more than 4 years up to now and ensures that the equipment is in place when a

367 flood arrives.

c. We showed that ADCP backscatter provides a viable method for estimating SSC during 369 floods when the signal is properly calibrated using SSC and Grain-Size Distribution (GSD) 370 data from measured samples. Our results show that vertical SSC distributed over the river 371 section is necessary to obtain a good calibration of the backscatter signal. When GSD was not 372 accounted for, Suspended Sediment Flux (SSF) was underestimated by 10\% (Fig. 2b).

$373 \mathrm{~d}$. ADCP allows to understand the structure of the solid flow throughout the channel section 374 and to better assess SSF, particularly during flood events.

375 e. Suspended sediment for the two floods investigated was dominated by silts and clays which 376 have an effect on the acoustic signal in water.

$377 \mathrm{f}$. Analysis of the sediment transported in suspension from samples collected at different 378 vertical depths showed uniform concentrations and GSD with depth. A vertical gradient was 379 visible only at peak discharge. 
g. Estimates of SSF based on ADCP data were similar to those based on surface samples collected at the automatic SORA station, located $32 \mathrm{~km}$ upstream. This similarity is linked to the weak vertical gradient in SSC for the two floods.

h. The two flood events analyzed for this study, separated by only a few days, showed clear differences in suspended SSC and SSF, with twice more suspended sediment transported during the first event. We attributed this decrease to the amount of sediment available from hillslope and bank erosion or more probably from resuspension within the riverbed. These differences in fluxes for similar magnitude events highlight the difficulty in estimating sediment fluxes precisely in the absence of continuous measurements.

\section{Acknowledgements}

This work was funded by the Regional Council of Bouches-du-Rhone and Rhone Sediment Observatory which is funded by the CNR, EDF, Agence de l'Eau RMC and PACA, Rhone and Languedoc-Roussillon regional councils. We are very grateful to help from the Syndicat Mixte d'Aménagement des Digues du Delta du Rhône et de la Mer.

\section{References}

Alvarez, L.G., Jones, S.E., 2002. Factors influencing suspended sediment flux in the Upper Gulf of California. Estuarine, Coastal and Shelf Science 54, 747-759 p.

Antonelli, C., Eyrolle, F., Rolland, B., Provansal, M., Sabatier, F., 2008. Suspended sediment and 137Cs fluxes during the exceptional December 2003 flood in the Rhone River, southeast France. Geomorphology 95, 350-360 p.

Antonelli, C., Provansal, M., Vella, C., 2004. Recent morphological changes of a channel in deltaïc environment. The case of the Rhône River, France. Geomorphology 57, 385-402.

Arnaud-Fassetta, G., Quisserne, D., Antonelli, C. 2003. Downstream grain-size distribution of 
surficial bed material and its hydro-geomorphological significance in a large and regulated river: the Rhône River in its delta area (France). Géomorphologie, 9, 33-49.

Blum, M., Tornqvist, T.E., 2000. Fluvial response to climate and sea-level changes: a review and lookforward. Sedimentology 47, 2-48.

Boateng, I., Bray, M., Hooke, J. 2012. Estimating the fluvial sediment input to the coastal sediment budget: A case study of Ghana. Geomorphology 138, 100-110.

Boudet L., Sabatier F., Radakovitch O. In press. Modelling of sediment transport pattern in the mouth of the Rhone delta: role of storm and flood events. Estuarine, Coastal and Shelf Science.

Bravard, J.P., Petit, F., 1997. Les cours d'eau. Dynamique du système fluvial. Armand Colin/Masson, Paris.

Cutroneo L., Castellano M., Pieracci A., Povero P., Tucci S., Capello M. 2012. The use of a combined monitoring system for following a turbid plume generated by dredging activity in a port. Journ. Soil Sed. 12, 797-809.

Defendi, V., Kovačević, V., Arena, F., Zaggia, L. 2010. Estimating sediment transport from acoustic measurements in the Venice Lagoon inlets. Continental Shelf Research 30, 883-893 p.

Dredging Research Ltd., 2003. The Sediview Method. Sediview Procedure Manual, DRL Software Ltd., Godalming, UK, 83pp.

Duclos, P.A., Lafite, R., Le Bot, S., Rivoalen, F., Cuvillier, A. 2013. Dynamics of Turbid Plumes Generated by Marine Aggregate Dredging: An Example of a Macrotidal Environment (the Bay of Seine, France). Journal of Coastal Research, 29 (6a), 25-37 p.

Eyrolle, F., Charmasson, S., Louvat, D., 2004. Plutonium isotopes in the lower reaches of the River Rhône over the period 1945-2000: fluxes towards the Mediterranean Sea and sedimentary inventories. J. Environ. Radioact. 74, 127-138. 
Eyrolle, F., Radakovitch O., Raimbault P., Charmasson S., Antonelli C., Ferrand E., Aubert D., Raccasi G., Jacquet S., Gurriaran R. 2012. Consequences of hydrological events on the delivery of suspended sediment and associated radionuclides from the Rhône River to the Mediterranean Sea. J. Soils Sediments 12, 1479-1495

Ferré, B., Guizien, K., Durrieu de Madron, X., Palanques, A., Guillén, J., Grémare, A., 2005. Fine-grained sediment dynamics during a strong storm event in the inner-shelf of the Gulf of Lion (NW Mediterranean), Cont. Shelf Res. 25 (19-20), 2410-2427.

Francois, R.E., Garrison, G.R., 1982. Sound absorption based upon ocean measurement, part II, J. Acoust. Soc. Am. 72 (6), 1870-1890.

Gartner, J.W., 2004. Estimating suspended solids concentrations from backscatter intensity measured by acoustic Doppler current profiler in San Francisco Bay, California. Marine Geology 211, 169-187 p.

Ghaffari, P., Azizpour, J., Noranian, M., Chegini, V., Tavakoli, V., Shah-Hosseini, M. 2011. Estimating suspended sediment concentrations using a broadband ADCP in Mahshahr tidal channel. Ocean Sci. Discuss., 8, 1601-1630.

Guerrero M., Szupiany R.N., Amsler M. 2011. Comparison of acoustic backscaterring techniques for suspended sediment investigations. Flow measurement and instrumentation. 22, 392-401.

Holdaway, G.P., Thorne, P.D., Flatt, D., Jones, S.E., Prandle, D. 1999. Comparison between $\mathrm{ADCP}$ and transmissometer measurements of suspended sediment concentration, Cont. Shelf Res., 19 (3), 421-441.

Hoitink, A.J.F., Hoekstra, P. 2005. Observations of suspended sediment from ADCP and OBS measurements in a mud-dominated environment. Coastal Engineering 52, 103-118.

Horowitz, A.J., Clarke, R.T., Merten, G.H. 2015. The effects of sample scheduling and sample numbers on estimates of the annual fluxes of suspended sediment in fluvial systems. 
Horowitz, A. J. 2008. Determining annual suspended sediment and sediment-associated trace element and nutrient fluxes. Sci. Total Environ. 400, 315-43.

Hu, J., Pan, J., Guo, X., Zheng, Q. 2011. A summary of special section: regional environmental oceanography in the South China Sea and its adjacent areas (REO-SCS). J. Oceanography 67, 675-676.

Inman, D.L., Jenkins, S.A., 1999. Climate change and the episodicity of sediment flux of small California Rivers. Journal of Geology 107, 251-270.

Kostaschuk, R., Best, J., Villard, P., Peakall, J., Franklin, M., 2005. Measuring flow velocity and sediment transport with an acoustic Doppler current profiler. Geomorphology 68, $25-37$.

Land, J.M., Bray, R.N., 2000. Acoustic measurement of suspended solids for monitoring of dredging and dredged material disposal. Journal of Dredging Engineering 2 (3), 1-17.

Limber, P.W., Patsch, K.B., Griggs, G.B., 2008. Coastal sediment budgets and the littoral cutoff diameter: a grain size threshold for quantifying active sediment inputs. Journal of Coastal Research 24, 122-133.

Meybeck, M., Laroche, L., Dürr, H., Syvitski, J. P. 2003. Global variability of daily total suspended solids and their fluxes in rivers. Glob. Planet. Change 39, 65-93.

Ollivier P., Radakovitch O., Hamelin B. (2011) Major and trace partition and fluxes in the Rhone river. Chem. Geol..285, 1-4; $15-31$.

Moatar F., Person G., Meybeck M., Coynel A., Etcheber H., Crouzet, P. 2006. The influence of contrasting suspended particulate matter transport regimes on the bias and precision of flux estimates. Science of the Total Environment, 370, 515-531.

Picouet, C., Hingray, B., Olivry, J.C., 2001. Empirical and conceptual modelling of the suspended sediment dynamics in a large tropical African river: the Upper Niger river 
basin. J. Hydrol. 250, 19-39 p.

479 Provansal M., Dufour S., Sabatier F., Antony E., Raccasi G., Robresco S. 2014. The geomphic

480

481

482

483

484

485

486

487

488

489

490

491

492

493

494

495

496

497

498

499

500

501

502 evolution and sediment balance of the lower Rhone River (southern France) over the last 130 years: hydropower dams versus other control factors. Geomorphology. 219, $27-$ 41.

Pont, D., Simonnet, J.P., Walter, A.V., 2002. Medium-term changes in suspended sediment delivery to the ocean: consequences of catchment heterogeneity and river management (Rhône River, France). Estuar. Coast. Shelf Sci. 54, 1-18.

Rijn, V. 1993. Principles of Sediment Transport in Rivers, Estuaries and Coastal Seas. Amsterdam: Aqua Publications, ISBN 90-800356-2-9 bound NUGI 816/831, 690 p.

Rovira, A., Batalla, R.J., Sala, M. 2005. Fluvial sediment budget of a Mediterranean river: the lower Tordera (Catalan Coastal Ranges, NE Spain). Catena 60, 19-42.

Sabatier, F., Maillet, G., Provansal, M., Fleury, T.J., Suanez, S., Vella, C. 2006. Sediment budget of the Rhône delta shoreface since the middle of the 19th century. Marine Geology 234, 143-157.

Schoellhamer, D.H., Wright A.S. 2003. Continuous measurement of suspended-sediment discharge in rivers by use of optical backscatterance sensors. Erosion and Sediment Transport Measurement in Rivers: Technological and Methodological Advances 1 (Proceedings of the Oslo Workshop, June 2002). IAHS Publ. 283.

Shi, Z., 2010. Tidal resuspension and transport processes of fine sediment within the river plume in the partially-mixed Changjiang estuary, China: a personal perspective, Geomorphology. 121, 133-151.

Syvitski J., Saito Y. 2007. Morphodynamics of deltas under the influence of humans. Global Planet. Change. 57, 3-4, 261-282.

Teledyne, RD Instruments, 2007. WorkHorse Rio Grande Acoustic Doppler Current Profiler. 
504

505

506

507

508

509

510

511

512

Tessier, C., Le Hir, P., Lurton, X., Castaing, P. 2008. Estimation de la matière en suspension à partir de l'intensité rétrodiffusée des courantomètres acoustiques à effet Doppler (ADCP). Comp. Rendu Geoscience 340, 57-67.

Unverricht, D., Nguyen, T.C, Heinrich, C., Szczuciński, W., Lahajnar, N., Stattegger, K. 2014. Suspended sediment dynamics during the inter-monsoon season in the subaqueous Mekong Delta and adjacent shelf, southern Vietnam. Journal of Asian Earth Sciences 79, Part A, 509-519.

Urick, R.J., 1983. Principles of Underwater Sound. McGraw-Hill Book.

Vörösmarty, C., Meybeck, M., Fekete, B., Sharma, K., Green, P., Syvitski, J.P.M., 2003. Anthropogenic sediment retention: major global-scale impact from the population of registered impoundments. Global and Planetary Change 39, 169-190.

Wall, G.R., Nystrom, E.A., Litten, S., 2008. Suspended sediment transport in the freshwater reach of the Hudson River estuary in eastern New York. Estuaries \& Coasts. 31, 542 553.

Walling, D.E., Webb, D.W., Woodward, J.C., 1992. Some sampling considerations in the design of effective strategies for monitoring sediment-associated transport. IAHS Publ. $210,279-288$.

Zebracki M., Eyrolle-Boyer F., Evrard O., Claval D., Mourier B., Gairoard S., Cagant X., Antonelli C. 2015. Tracing the origin of suspended sediment in a large Mediterranean river by combining continuous river monitoring and measurement of artificial and natural radionuclides. Science of the Total Environment. 502, 122-132.

\section{CAPTIONS}


Figure 1. a). The Rhone River Delta highlighting the location of the Barcarin ferry crossing on the Grand Rhone and the city of Arles where the SORA station is located. b) An aerial photo of the Barcarin ferry landing. The white dotted line shows the average trajectory of the ferry between the right and left banks of the Grand Rhone. The white dots mark the locations where the ADCP measurements automatically start and stop.

Figure 2. a) Mean daily discharge $\left(\mathrm{m}^{3} \cdot \mathrm{s}^{-1}\right)$ of the Rhone river for the month of November, 2012 highlighting the two annual events $\mathrm{N}-12\left(12^{\text {th }}\right.$ Nov. $)$ and N-29 (29 $9^{\text {th }}$ Nov $)$ that were monitored in this study. The black squares indicate the days on which the flow was sampled. Discharge measurements were conducted at the SORA station in Arles (32km upstream) and provided by the CNR. b) a cross-sectional view of the channel showing in red the locations where samples were collected at different depths in the water column.

Figure 3. a) Distribution of flow velocities measured with the Barcarin ferry ADCP during the N-12 flood. The date and mean current speed are indicated in each panel. b). Relationship between mean Barcarin ADCP flow velocities and corresponding discharge measured at the SORA station at Arles.

Figure 4. Suspended sediment concentrations (mg. ${ }^{-1}$ ) with depth at the three sampling locations (left and right banks and middle channel) for the N-12 (black) and N-29 (white) floods. The legend refers to the sampling date, and the measurements associated with each flood peak are highlighted.

Figure 5. The relative grain-size fractions: clay, silt, and sand, for each of the suspended samples collected at 0.5 $\mathrm{m}$ from the surface of the flow throughout the two monitored floods. During the two flood events, there are no daily vertical variation of sediment grain size.

Figure 6. An example of SSC distribution along the cross section based on ADCP backscatter calibrated (a) without accounting for GSD and (b) with GSD correction included.

Figure 7. A-G) Suspended sediment flux based on corrected ADCP measurements across the river for the N-12 flood. The date and total flux $\left(\mathrm{t}^{-1}\right)$ are indicated in each panel. $\mathrm{H}$ ) Mean daily discharge measured at Barcarin and mean daily suspended sediment flux estimated from ADCP measurements for the $\mathrm{N}-12$ flood.

Figure 8. A - Z) Suspended sediment flux based on corrected ADCP measurements across the river for the N-29 flood. The date and total flux $\left(\mathrm{t} .^{-1}\right)$ are indicated in each panel. H) Mean daily discharge at Barcarin and mean daily suspended sediment flux estimated from ADCP measurements for the N-29 flood.

Figure 9. Comparison of suspended sediment flux (tons/day) during the rising and falling limbs of the 2 monitored floods (N-12 and N-29) based on measurements from automated surface samples at the SORA station in Arles and calibrated ADCP backscatter at the Barcarin crossing. 


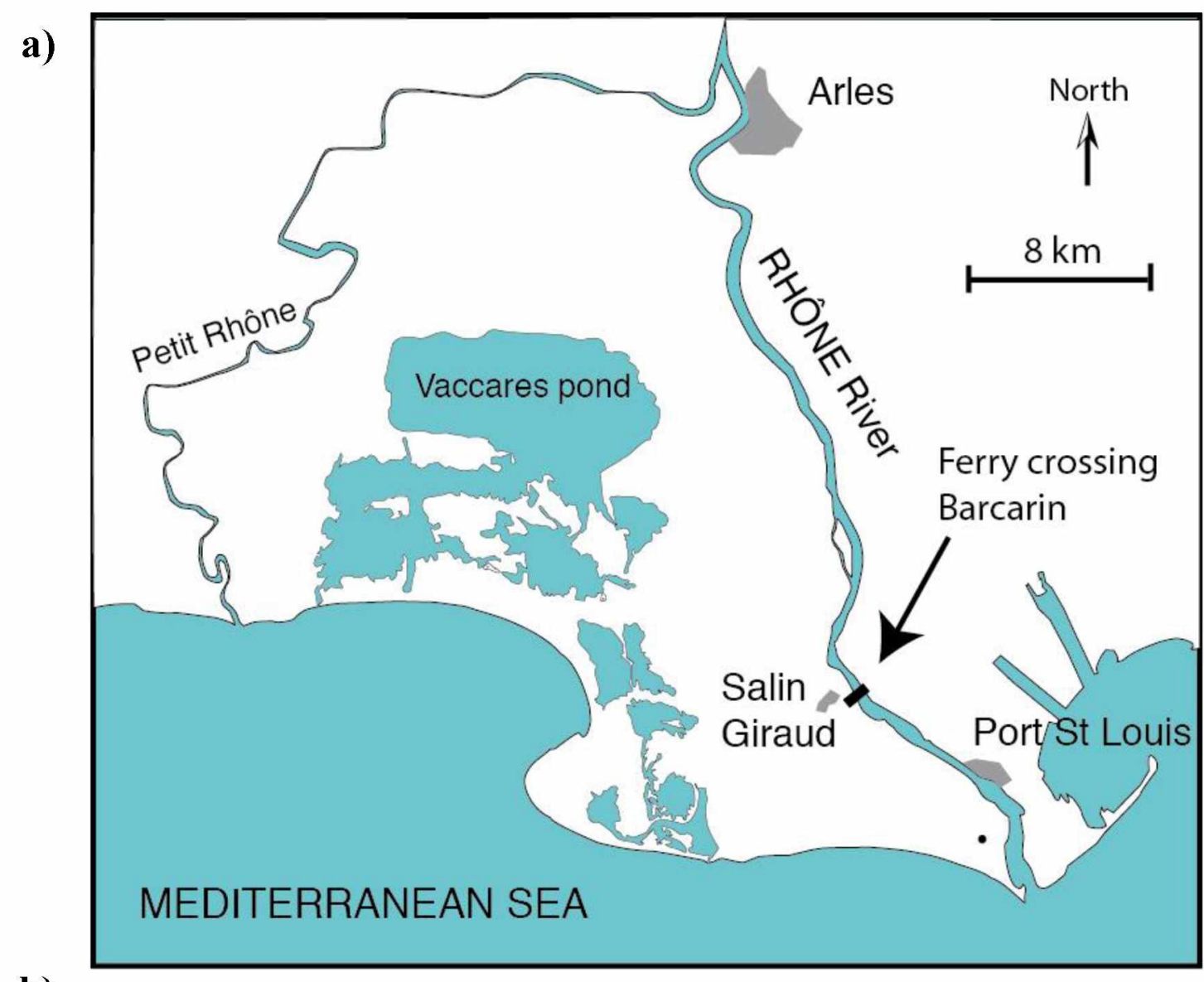

b)

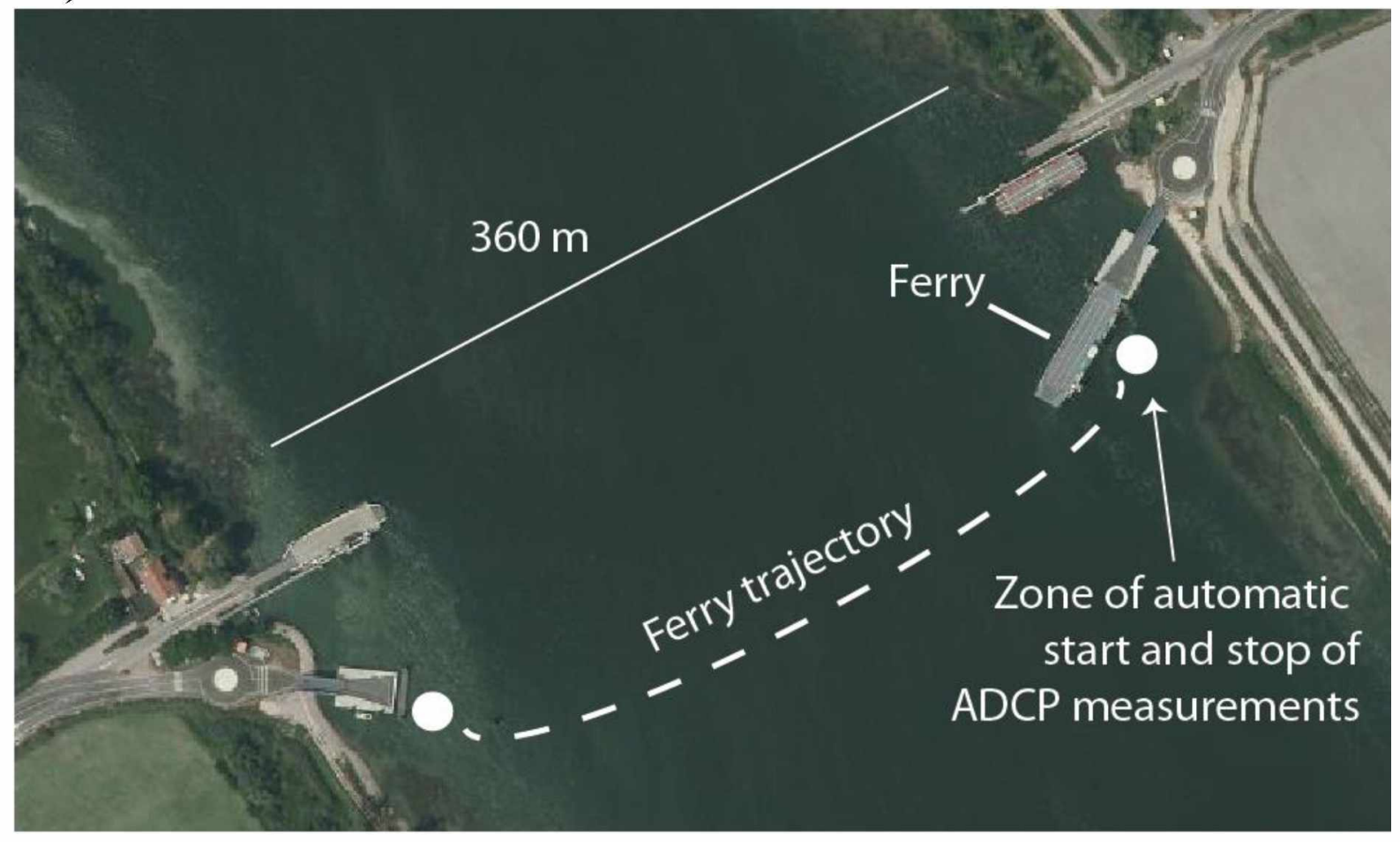




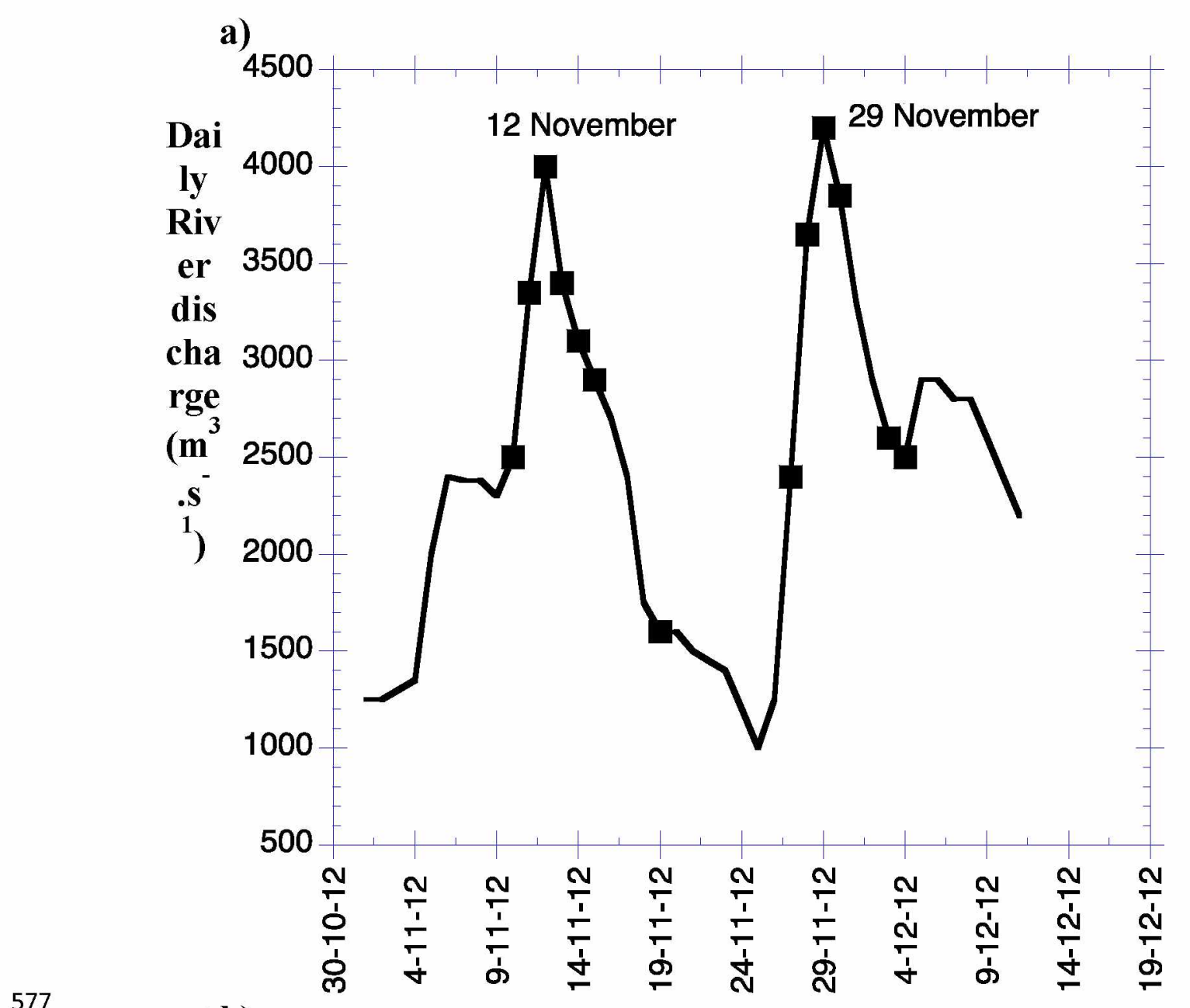

577

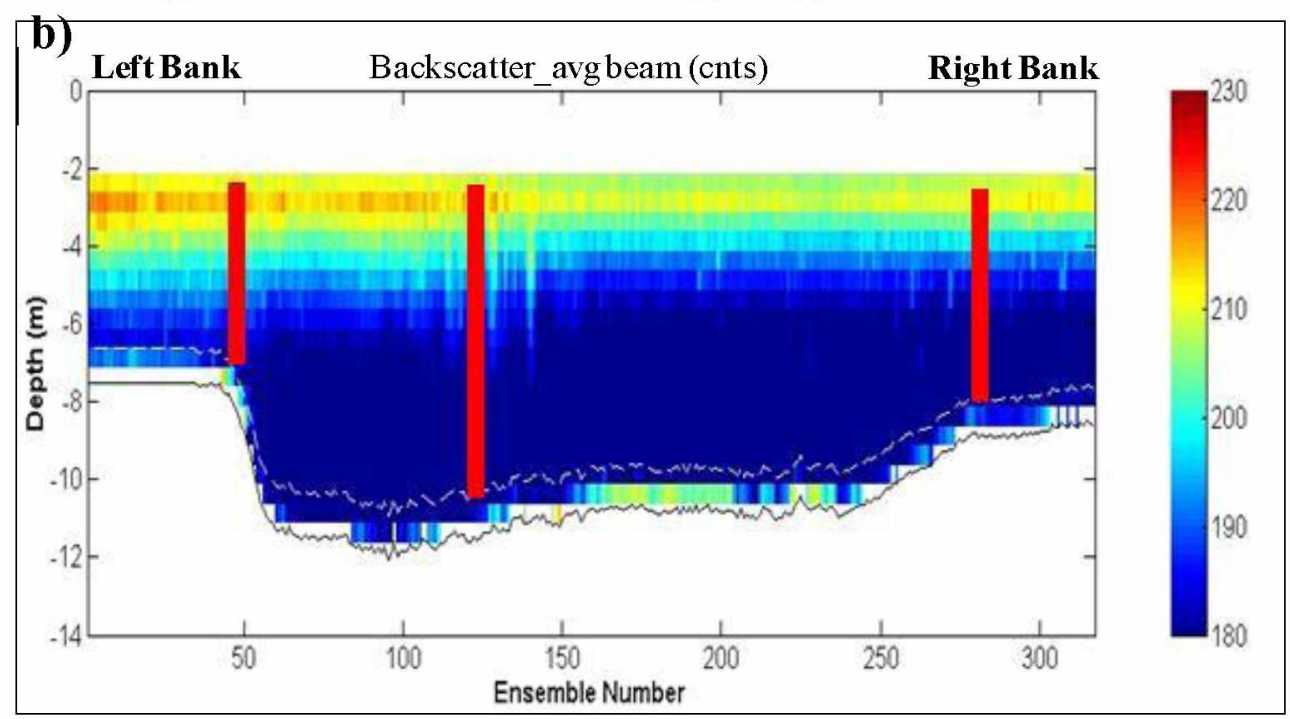

Figure 2. 

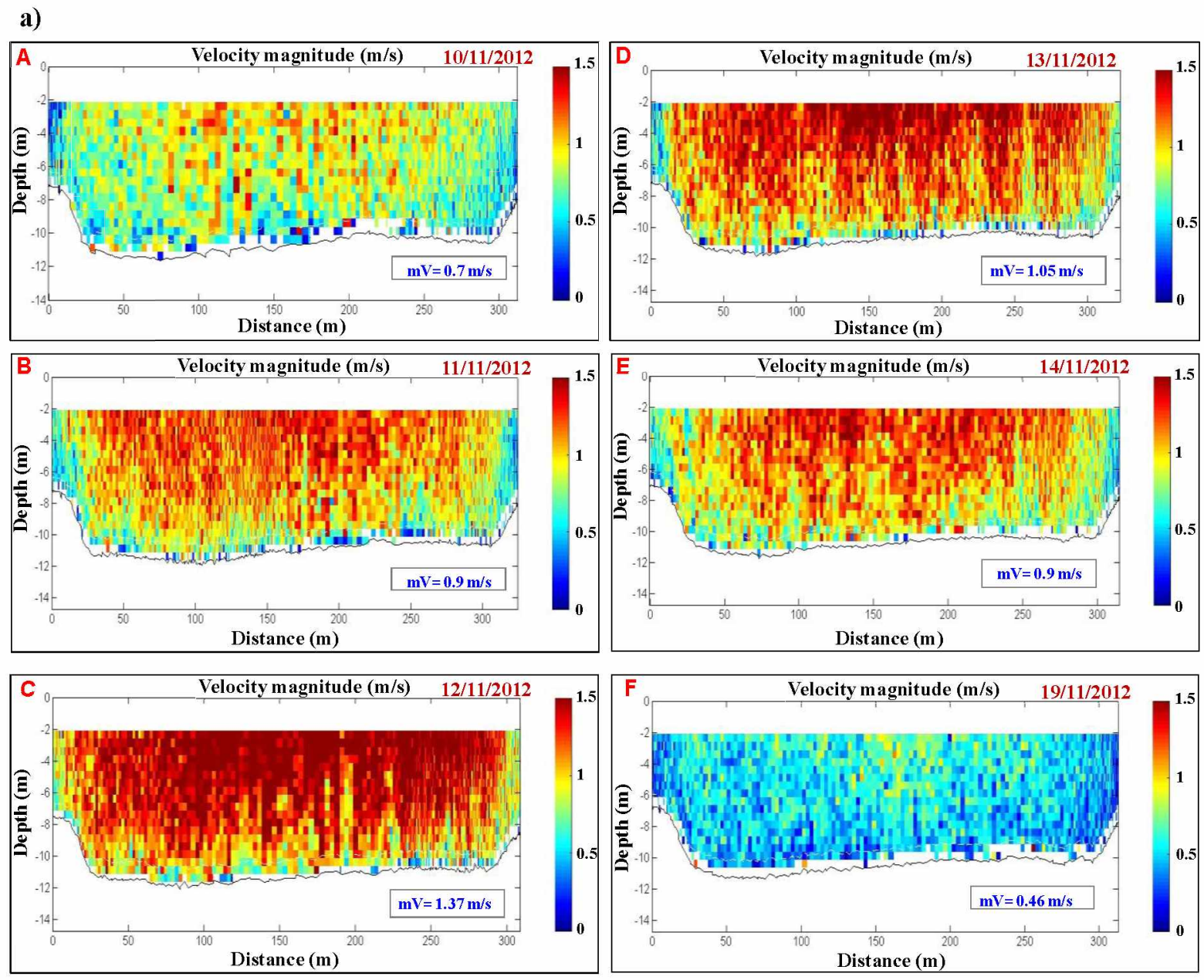

590

591

b) 1.6
Curr 1.4
ent

spee 1.2$\}$

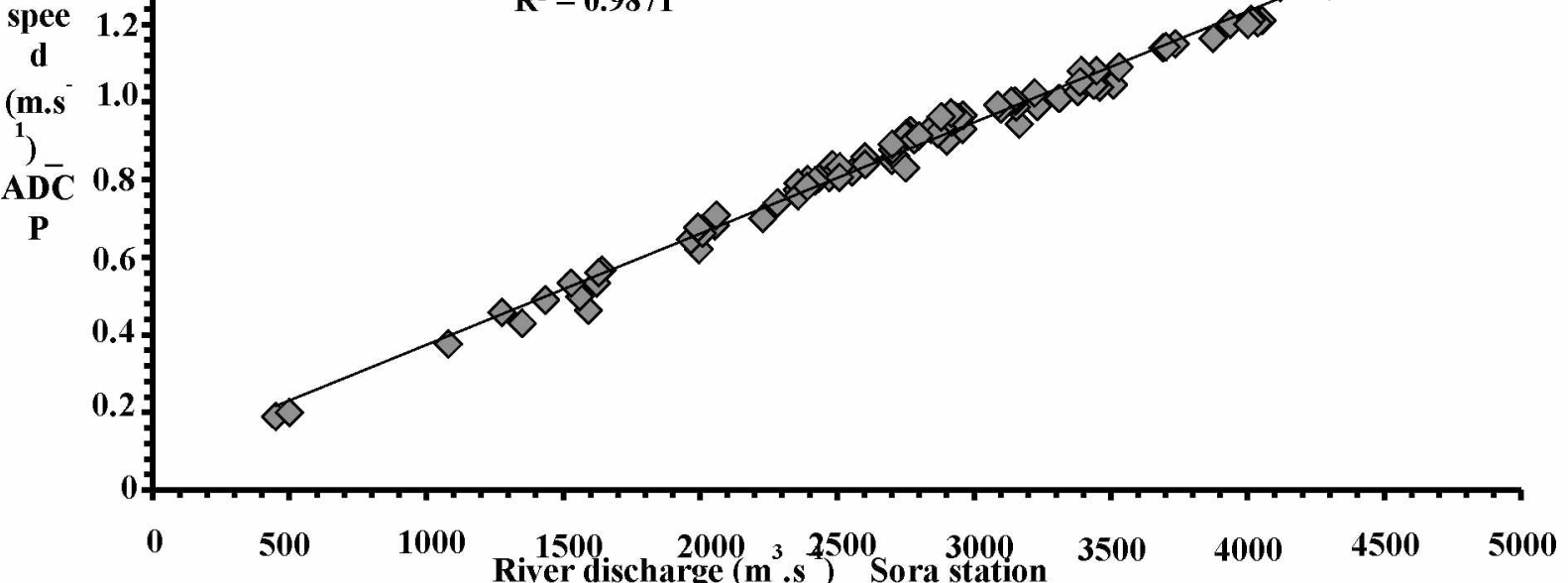

Figure 3.

596

597

598

599

600 

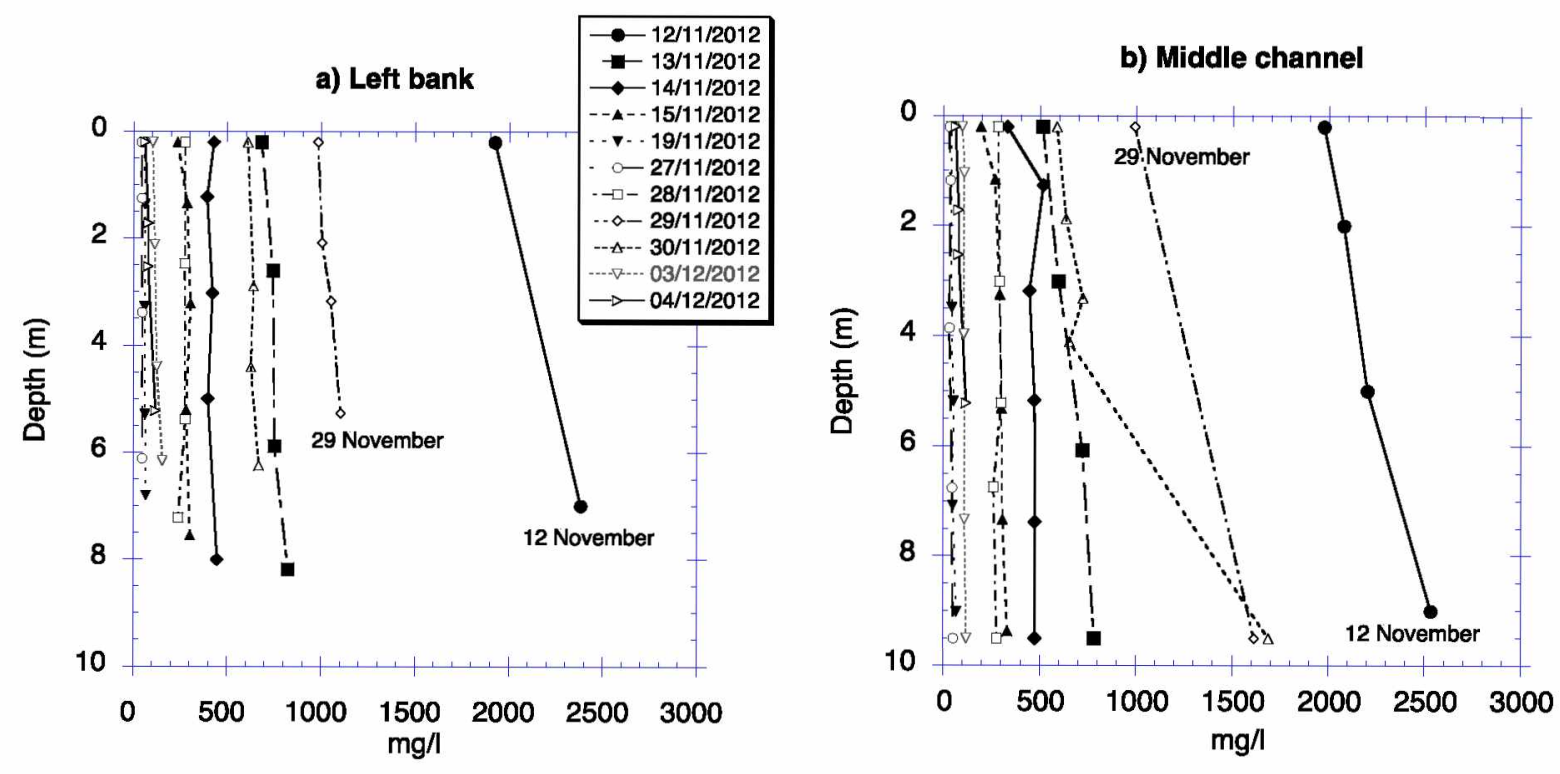

601

c) Right bank

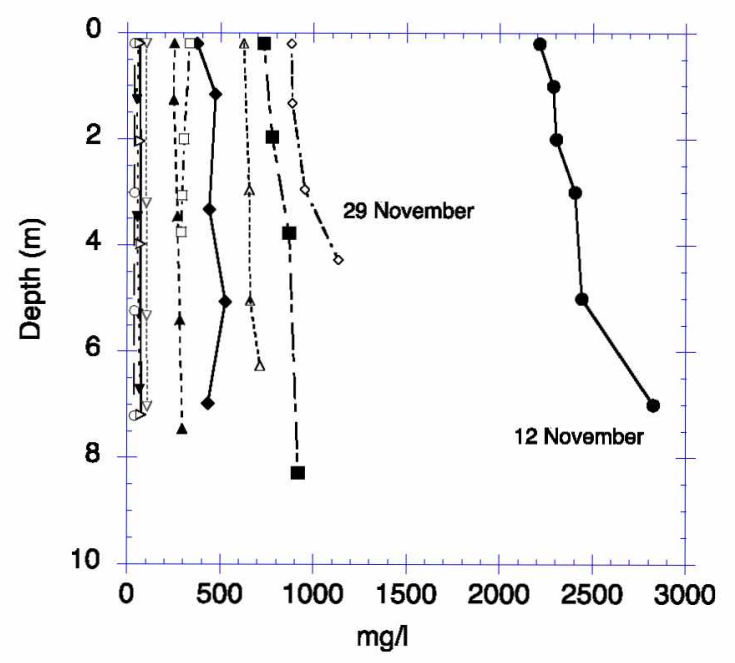

602

Figure 4.

604

605

606

607

608

609

610

611

612 


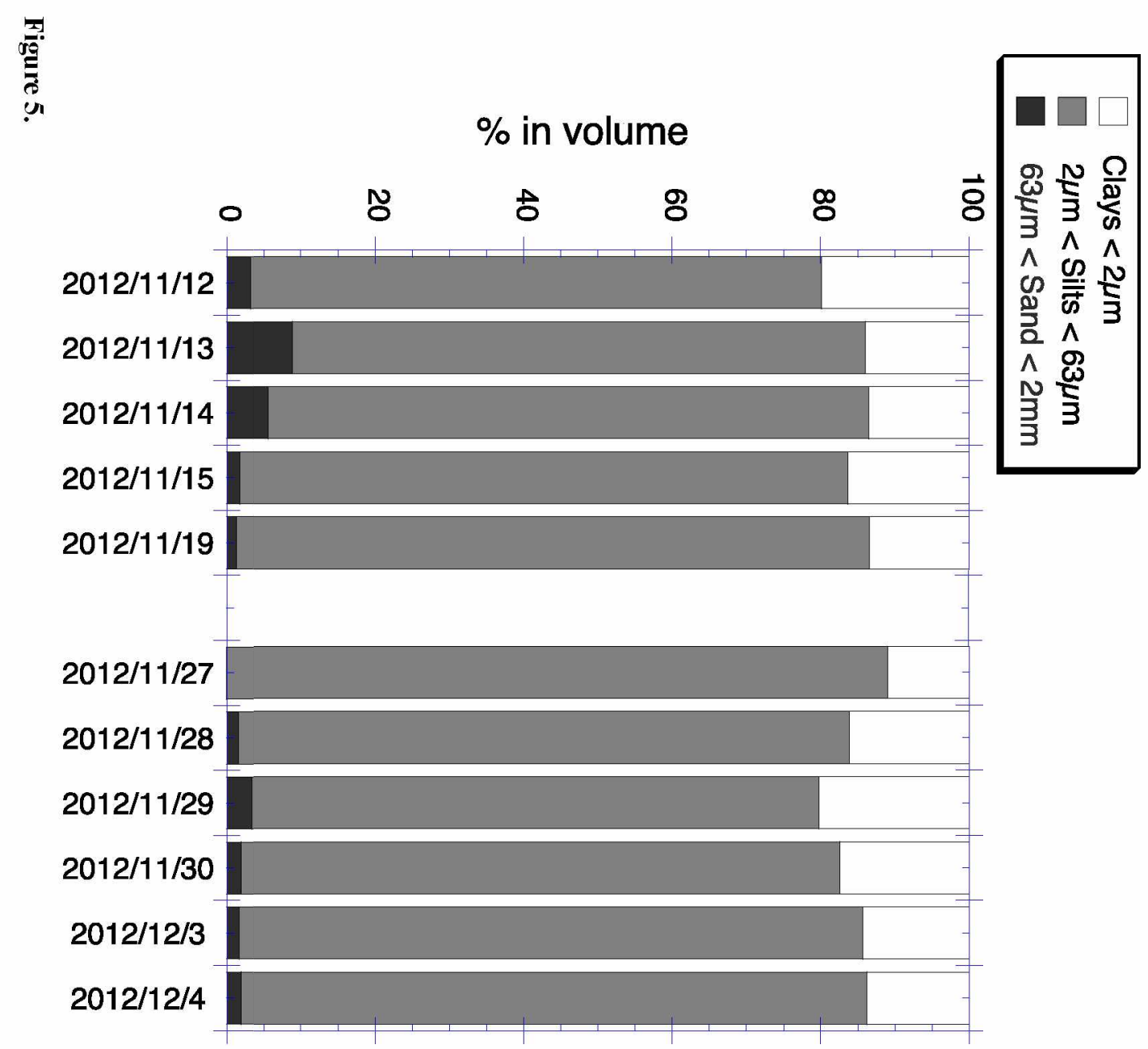


a). Conversion of backscatter to SSC with water samples

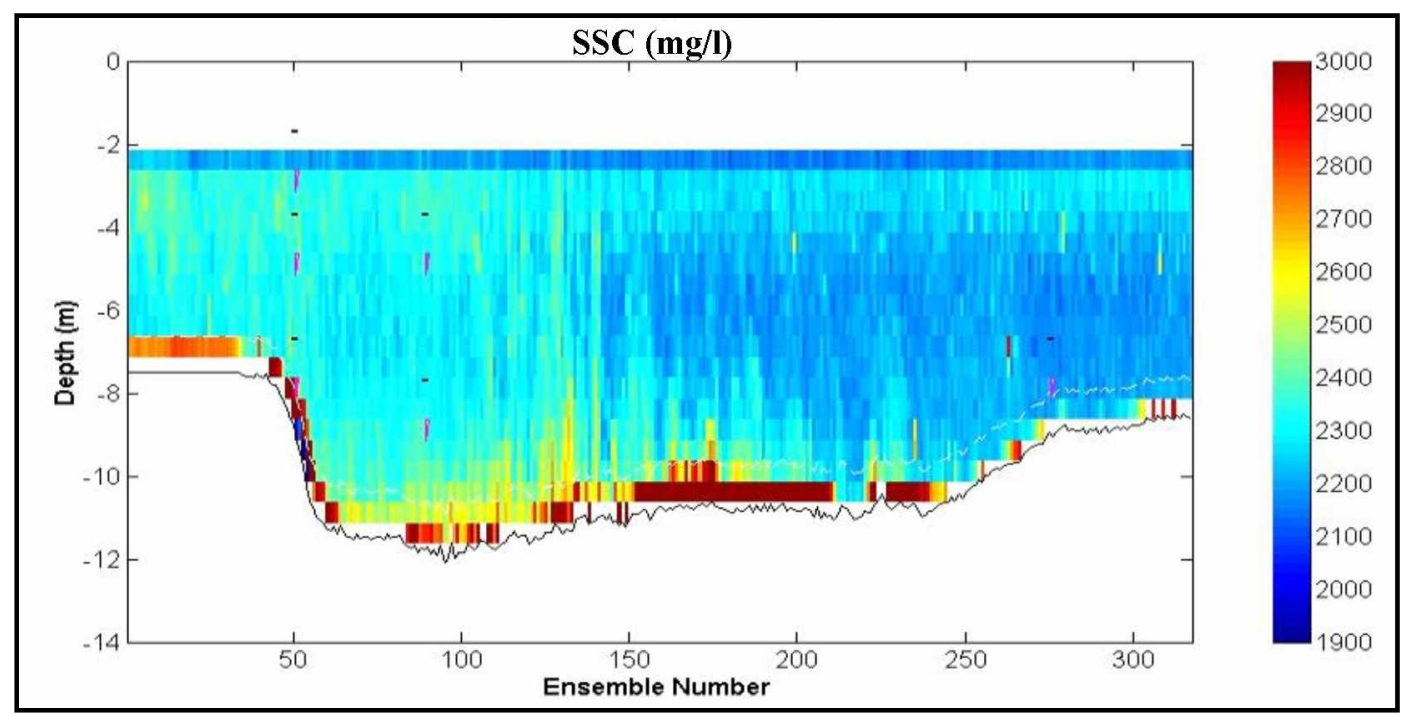

b). Signal correction with grain size distribution

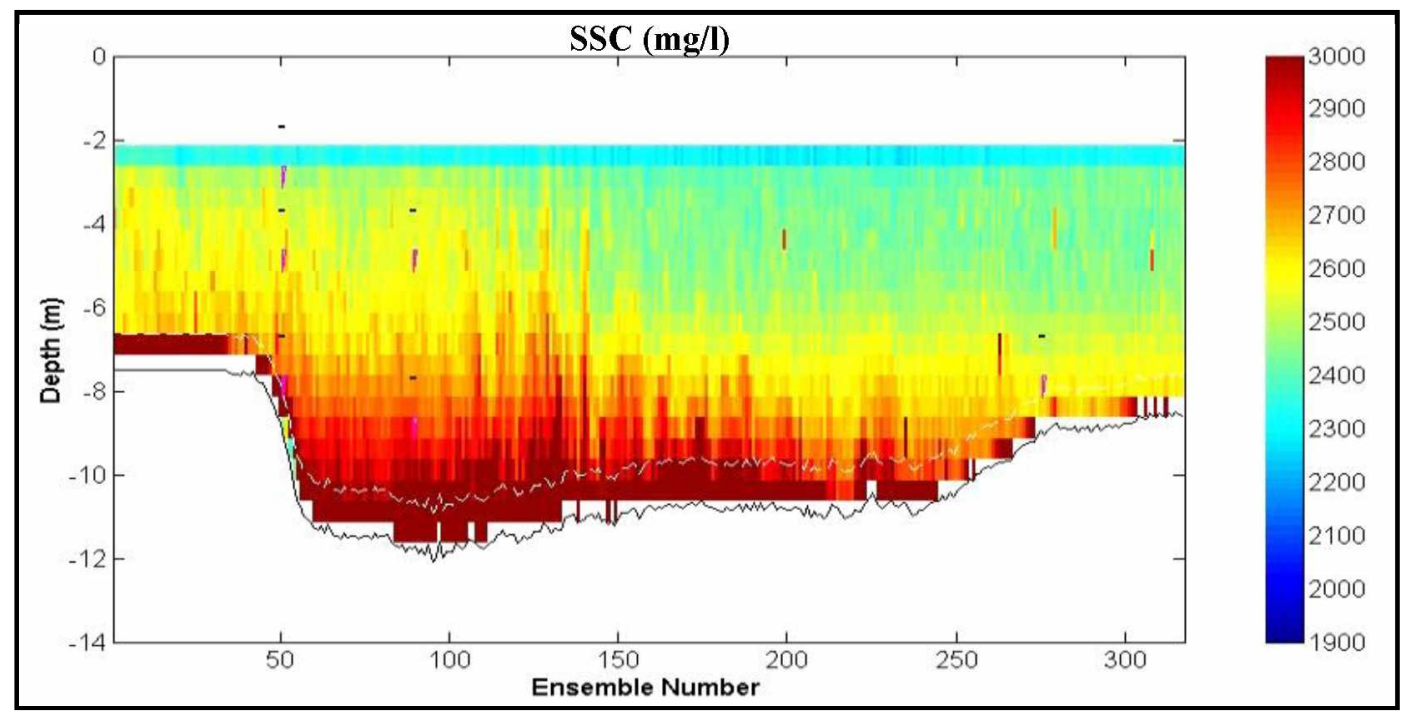

Figure 6 


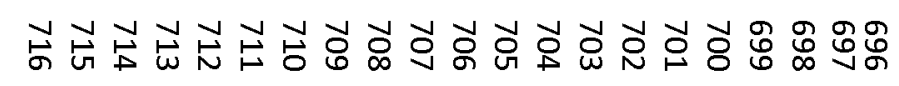

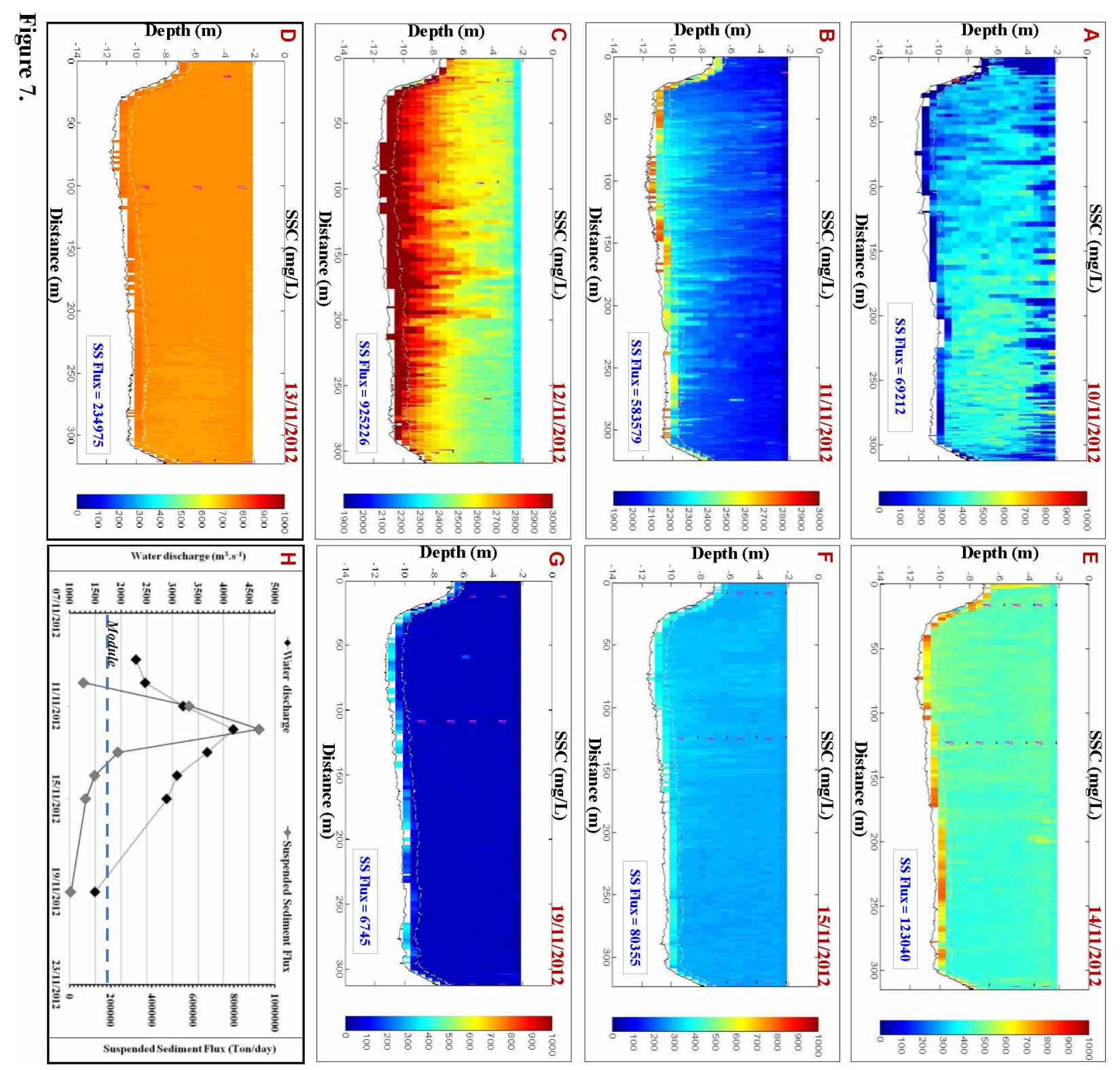



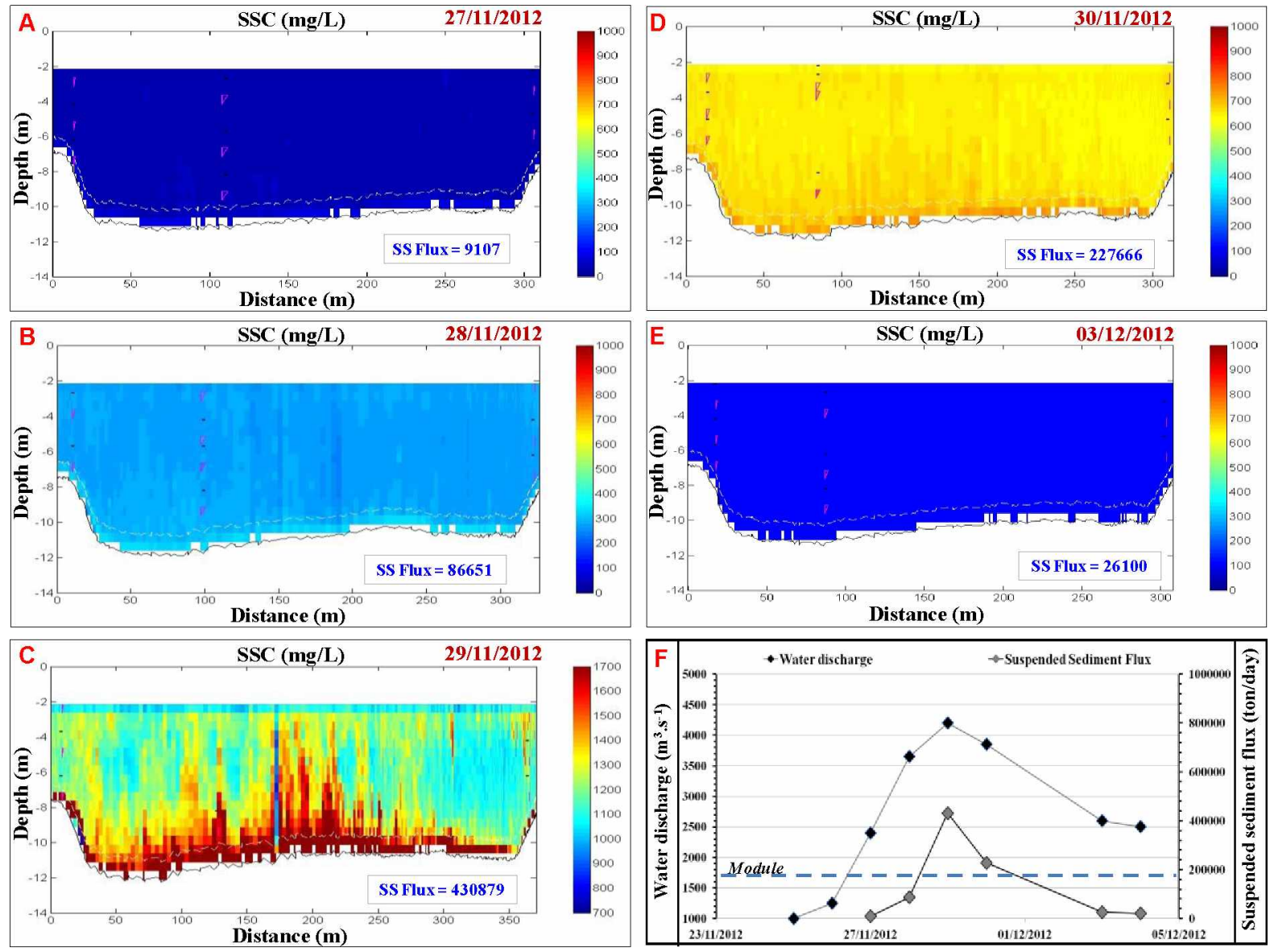

Figure 8. 


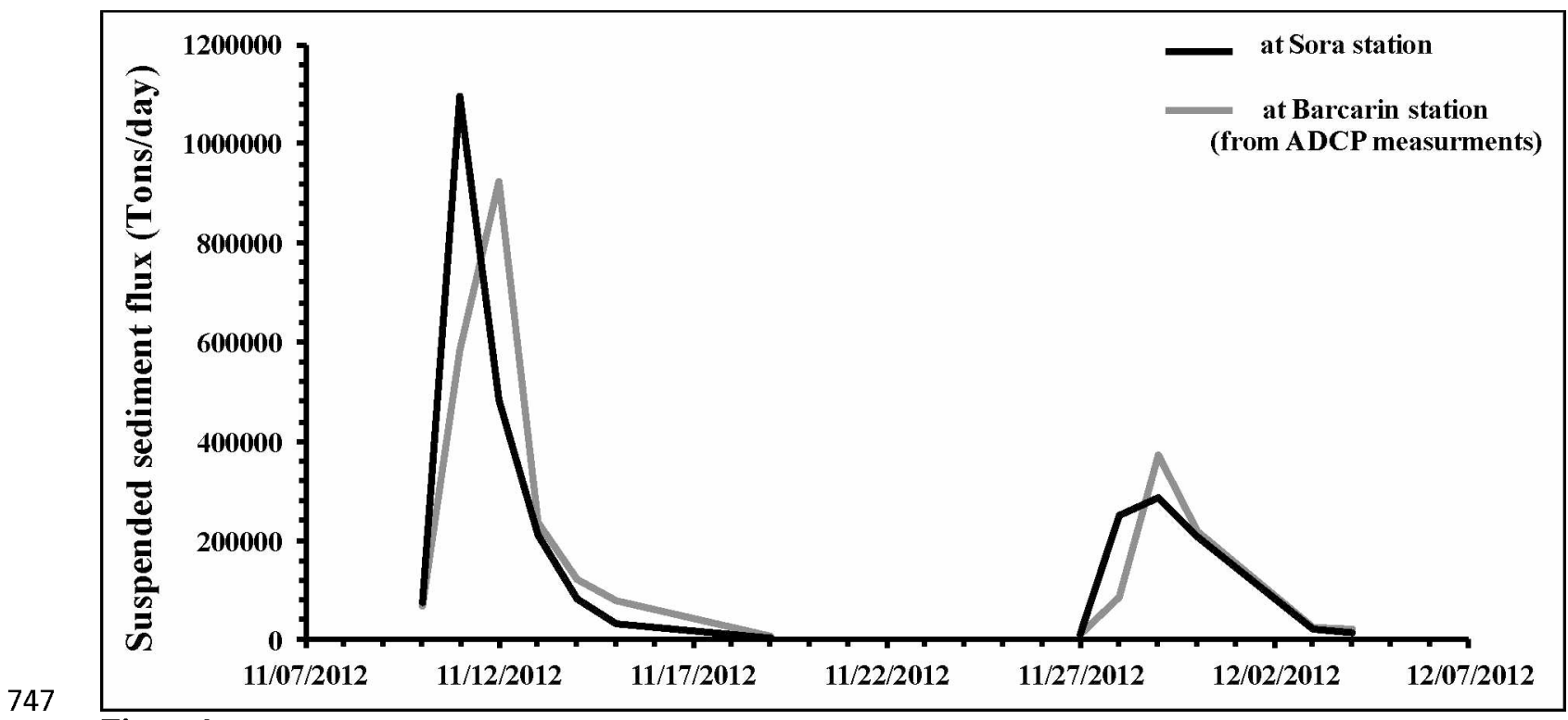

748 Figure 9.

749

750

751

752

753

754

755

756

757

758 